\title{
Has ethics changed or is it currently not being applied?
}

\author{
A ética mudou ou, atualmente, ela não é plenamente exercida?
}

\author{
TCBC Fernando CoRdeIRo
}

W riting on moral, ethics, and especially on medical ethics in modern times and, who knows, at any time, always brings the discussions on human conduct, its required coding between good and evil and, especially, an attempt of society to standardize the relations between people and groups.

Several thinkers and writers have left their concepts on the subject. I personally always like to avail myself of the dictionaries as reference for concepts. So, looking at the New Dictionary Aurelius, I find: ethics - "the study of assessment judgments concerning human behavior, susceptible to qualification from the point of view of good and evil, whether in respect of a given society or absolutely". One could confuse it with the concept of moral, whose definition is: "set of rules of conduct considered as valid, whether absolutely to any time or place, or to a particular group or person." The big difference is in the ethics code and its usefulness as a beacon of professional activities. But back to the topic, if medical ethics has been so often defined and coded, from the Hippocratic times to our present time, under the aegis of the current Code of Medical Ethics, 1988, why this issue still hangs over our heads ?

According to the jurist doctor, professor Genival Veloso de França, one of the great thinkers of the matter, one can no longer believe that Medical Ethics is still a corporatist instrument. Today, this code has gained space and freedom, affecting not only the doctor-patient-society relationship, but also political and social relations, which requires the doctor to take more realistic positions towards the current social life. In this sense, we can no longer imagine that that physician, in a paternalistic way, knew it all, wrote prescriptions, ordered compliance and demanded the result from the patient. Today the society questions every fact, every system and requires evidence that the conduct established will have the best result to their problems.

We increasingly hear and see reported in all the media that physicians would be willfully performing unnecessary operations, with prosthesis, orthotics and extremely costly equipment; cesarean section instead of vaginal delivery, vaginal delivery with mutilating episiotomy, for the sole purpose of financial gain. Does this happen because one does not follow the coded Medical Ethics? Does the financial interests outweigh those expected to disciples of Hippocrates?

At first glance, the two previous questions have affirmative answers, but is it the truth?
We have some problems to be solved and these begin with the demystifying of medicine itself. The medical art is not to cure, but to find possible answers backed by an investigative format. The doctor does not know what patients have, but imagines the various possibilities after a careful and methodical investigation, electing that hypothesis most likely to be the cause of the patient's problems. Nor can he/she be sure about the results that certain procedures or treatment will have on the patientdisease binomial. Various possibilities are tested and the result can be presented in a positive or negative way. Some doctors think they know everything and when the results did not benefit them, only then, they try to explain the reasons for failure. Similarly, some patients believe that the doctor has an obligation to precisely set diagnoses, drugs, procedures, especially at low cost and, when this does not happen, the responsibility rests solely with the doctor, with his greedy spirit, with the incompetence of the education system or with the controller system that does not meet its competences.

The correct and most complete information possible can settle this first conflict. To use the time to explain how to research, what is the need of certain laboratory tests and mainly explain mechanisms of action of many medications, as well as possible adverse results, does not mean a waste of time, but a doctor obligation, since the final decision will be, in most cases, in the hands of the patient. Also, to accept the demands of patients regarding results, expenses and equipment does not mean the better, easier, or more convenient alternative to the doctor. Sometimes they become the most painful, as they impose responsibilities that would not be part of the service contract and will certainly be required later.

We must not forget that medicine is an occupation and, in consequence, their professional need and are entitled to remuneration consistent with personal and family survival, with spending for medical training and also for continuing education. The form of compensation, as in any other professional activity, is expected to happen in a lawful manner, within the given social parameters.

The empathy in doctor-patient relationship, often questioned, because doctors would not have time or patience to achieve it, is not related to the qualification or to medical ethics itself, but with the human, social and individual quality.

Unfortunately, we are also a product of society we live in and in a world where advertising seems to be 
the most important and easiest way to achieve social Olympus, its use in professional activity has proven increasingly deleterious to the professional image and, especially, due to its legal implications through the reversal of the liability of subjective to objective, characterizing certain acts as result ones.

And why not also remember the politics of our times? Society demands administrative responsibility of our politicians, requires lower costs and they now seek to respond to their inquisitors, finding masterful formulas to reduce costs, giving a stamp of irresponsibility to the doctor who does not fulfill his/her task without spending, forgetting the requirement of better use and especially the individual wills of citizens. So cesarean is expensive? It is not the best procedure. But can the patient require? If particular, no problem, but if public, the doctor failed in its Code of Ethics and thus the responsibility is no longer of the administrator, but of those who do not fulfill the imposed administrative rules.

Although ethics is a coding modifiable by society, I believe that there has been no recent changes or even a reduction in its weight on the day of the doctor and its compliance.

Still, we are repulsed by the Dantesque news of the not indicated implant prosthesis, operations and even consultations occurred in unfavorable conditions.

As Oscar Wilde said, "we call ethics the range of things that people do when everyone is watching. The range of things that people do when nobody is looking is called character ", that is, we will continue to find unscrupulous people, companies seeking profit above all, and governments interested in perpetuating the benefits of its participants.

We must fight on all fronts: to educate our children, to give them the moral values we want in our family environment, to require that medical schools are committed to reinforcing these values and to teach the ethical and professional concepts, to question measures that may denigrate the medical professional activity, and fundamentally to believe in the human being moral values. 